\title{
Benefits to Down's syndrome children through training their mothers
}

\author{
R. T. BIDDER ${ }^{\star}$, G. BRYANT $†$, and O. P. GRAY \\ From the Department of Child Health, Welsh National School of Medicine, Cardiff
}

\begin{abstract}
Bidder, R. T., Bryant, G., and Gray, O. P. (1975). Archives of Disease in Childhood, 50, 383. Benefits to Down's syndrome children through training their mothers. This study investigated the hypothesis that training of mothers with Down's syndrome children would be beneficial both to the child and parents. The mothers were taught behaviour modification techniques based on learning theory and were given group discussions on dealing with their family or personal problems. The subjects were 16 mothers with a Down's syndrome child, divided into two groups on the basis of their child's sex and chronological and mental ages. The Griffiths Scale was used for assessment. The mothers in the treatment group received 12 sessions of training and group counselling over a 6-month period, whereas the control mothers received no additional attention except the usual routine from the general practitioner and health visitor. The results show clear gains to both the child and mother in the treatment group. The child improved, especially in language development as well as in the other areas, and the mother gained more confidence and competence in her daily management of the child.
\end{abstract}

Children with Down's syndrome are often placid and undemanding so that they receive little specific training and attention in their early life (Carr, 1971; Mittler, 1974; Santostefano and Stayton, 1967). Nevertheless, they have a potential for learning which can be developed by appropriate methods (Brinkworth, 1967b, 1967-71, 1972; Cunningham and Jeffree, 1971; Jones, 1974). It has been shown that their speech and language can be improved by positive reinforcement (Sloan, Johnston, and Harris, 1968; MacAulay, 1968). Down's syndrome children reared at home develop faster than those in institutions, confirming their ability to respond to a warm and stimulating environment (Centerwall and Centerwall, 1960; Stedman and Eichorn, 1964; Melyn and White, 1973; Levinson, Friedman, and Stamps, 1955).

This study was designed to measure differences in the rate of development of the Down's syndrome child after the mother had been instructed in and used behaviour modification techniques in training her own child. The study compared the progress of a control and a treatment group after a 6-month

Received 1 November 1974.

Present addresses: *Preswylfa Child and Family Centre, Clive Road, Cardiff.

+Cardiff Community Health Sector, Greyfriars Road, Cardiff. period. The study also investigated the therapeutic value of the skilled direction given to the parents.

\section{Materials and methods}

Sixteen mothers with a Down's syndrome child were chosen for this study. The children were aged from 12 to 33 months and their mental age ranged from $9 \frac{1}{2}$ to $22 \frac{1}{2}$ months at their first assessment by the Griffiths Mental Development Scales (Griffiths, 1954, 1970).

The children were divided into two groups matched according to sex, and chronological and mental ages. Each group had 2 girls and 6 boys. The mean chronological age of the treatment group was 23.8 months and the control group 24. 5 months; the mean mental age of the treatment group was 16.6 months and the control group 14.8 months at the beginning of the study. The mothers in one group were given specific training in behaviour modification techniques for 6 months and the others received the usual attention from the health visitor and general practitioner.

The children's mental development was assessed by the Griffiths test when first seen and again 6 months later. These tests were carried out by the same person who was not aware of the child's group. At the end of 6 months the mothers in the treatment group were asked to provide spontaneous written comments about the group meetings.

The mothers in the treatment group had 12 training 
periods during 6 months. There was also one meeting for the fathers and baby minders. The sessions were orginally given once a week for a total of 4 weeks, then a further 4 sessions at fortnightly intervals, and the last 4 sessions were given once per month. Each meeting was divided into two separate sections for different treatments. The first $1 \frac{1}{2}$ hours was spent teaching mothers behaviour modification techniques found to be beneficial in training mentally retarded children (Bensberg, Colwell, and Cassel, 1965; Berkowitz and Graziano, 1972; Bricker and Larsen, 1968; Brinkworth, 1967a, 1967-71, 1972; Goldstein, 1964; Howlin et al., 1973; Cunningham and Jeffree, 1971; Patterson and Gullion, 1968; Rentfrow and Rentfrow, 1969; Santostefano and Stayton, 1967; Watson, 1972, 1973). In these sessions mothers were given the aims for training their own child and were encouraged to discuss the problems they encountered in achieving aims. In the latter part of each session (about 45 minutes) a discussion group was held when the mothers expressed and shared their family and personal problems resulting from their Down's syndrome child. Though the sessions were directed to the mothers, they were instructed how to involve the whole family in the treatment plan. This instruction was also given to the fathers and baby minders.

The teaching aids used included tape recordings and demonstrations through an observation mirror. These were then discussed and modified if necessary.

The training programme emphasized the importance of early language development, both verbal comprehension and verbal expression; manipulative activities, especially construction; self-help skills such as selffeeding, toilet training, self-dressing, helping in the house; and general co-operation. The aims were tailored for each child and were advanced in small steps based on the child's recent achievements.

Mothers were asked to keep frequent records throughout the 6 months. For the first 2 weeks the records were those of the child's activities in the home. When the mothers understood their child's programme they made daily recordings of their training sessions stating the length and number of sessions as well as the child's response. These recordings were used to decide whether the mother's techniques needed modification. The mothers took about 10 minutes to do the home training sessions. They repeated them twice or more daily. Mothers were taught to modify their daily routine in order to have the maximal verbal communication with the child and to involve the child in their household duties in order to encourage the child's independence and competence in self-care.

\section{Results}

The Griffiths Scale results were compared using the difference of the mental age in months between the assessments before and after the 6-month observation. Statistical analysis of variance was calculated (Maxwell, 1970) and the difference of means and ranges in each group for the various subscales is shown in the Fig. This analysis shows a highly significant difference in the language development $(P<0.01)$. The infants in the treatment group had advanced at the mean rate of 6.56 months, range 3-13 months, whereas the control group had only advanced at the mean rate of 2.56 months, range $1-5$ months, on the language scale. There was also significant difference in the performance scale $(P<0.05)$, the mean value for the treatment group was 7 months, range $5 \frac{1}{2}-11 \frac{1}{2}$ months, whereas the mean value for the control group was $4 \cdot 37$ months, range $\frac{1}{2}-8$ months. The personal-social scale difference did not reach statistical significance but showed a trend.

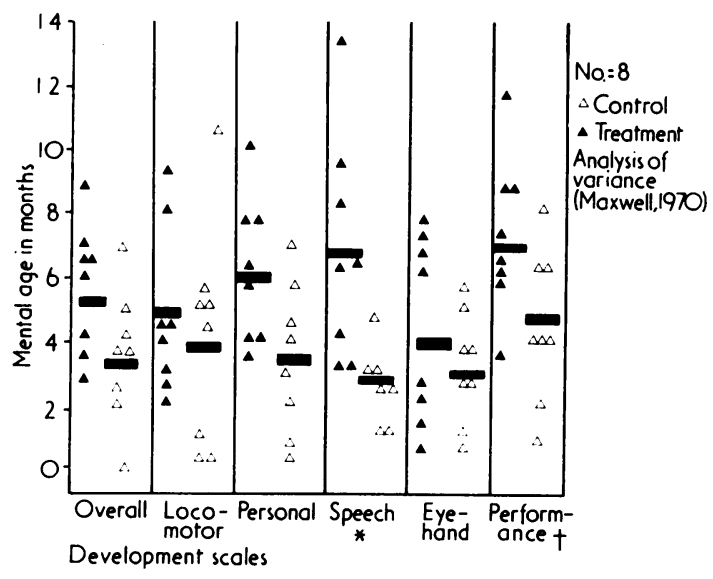

FIG.-Differences in mental age in months of two groups of children after 6 months' training period (Griffiths Scale). Horizontal lines indicate mean value in each group. ${ }^{\star} P<0.01 ;+P<0.05$.

The mothers of the treatment group were asked to comment in writing on their treatment at the end of the treatment period. The comments of 7 mothers are given in the Table. One mother gave only one sentence (she had attended the least).

\section{Discussion}

These results confirmed the original hypothesis that training of mothers with Down's syndrome children is of benefit to the child by facilitating his developmental progress, and to the parents by giving them increased understanding of the management of their child. The treatment group showed greater improvement by higher differences between the initial and later assessments than the control group in all the areas measured except locomotion. The lack of improvement in the locomotion score 
TABLE

Analysis of written statements of 7 mothers about the training sessions

\begin{tabular}{l|c}
\hline & No. of mothers \\
\hline $\begin{array}{l}\text { Gained teaching skills } \\
\text { (A) Gave techniques }\end{array}$ & 7 \\
(B) Knew goals for their child & 7 \\
C) Received more knowledge about their & 6 \\
$\quad$ child's future & 4 \\
Morale improved & 7 \\
(A) Felt encouraged to try harder & 7 \\
(B) No longer felt alone & 5 \\
(C) Appreciated ability to discuss & 7 \\
& problems
\end{tabular}

Note: The majority of the mothers appreciated the help but one mother reported that she would have liked more norms of development. This mother had 2 other older children. Another mother felt some of the techniques were not practical enough.

has been reported previously by Brinkworth (1972) and may be due to predetermined limited biological maturation which prohibits any advance in the rate of development. An alternative explanation is the deliberate lack of emphasis in advice on locomotor development in the treatment sessions. It was considered not important to devote much time to locomotor development since most Down's syndrome children eventually walk and move easily. It is likely that the improvements measured were due to the specific instructions given, but an alternative explanation could be that they were the direct result of the extra attention given to the mothers. However, they are unlikely to be a placebo-effect because the gains measured were in just those areas where special emphasis was made in the training, the language and performance skills.

It is interesting to note that the mothers in the treatment group observed the progress of their child's development intensely; for instance, after only 2 months of group meetings the mothers had statements in their charts such as 'starting to improve', 'understands better', 'is more inquisitive'. Their observations were confirmed by the assessment evaluation. It should be pointed out this is a relatively short study period and there is no evidence that these gains are more than temporary. However, even if the present rate of progress is not maintained the children are likely to have a permanent benefit from the treatment received in the trial.

The mothers' spontaneous written reports showed similar statements suggesting that the sessions gave them skills and techniques such as increased knowledge, confidence to carry out their plans, and in coping with their child, and also that they were good for their morale; they felt that they were not alone with their problem, were encouraged, and had fewer feelings of inadequacy.

There were no objective measurements of the child's behaviour as the Griffiths Scale does not measure behaviour, nevertheless we received several comments from outside observers such as nursery teachers and neighbours, that there was marked improvement in the child's behaviour. They were described as more independent and more co-operative.

The Griffiths Scale has a few items which are dependent on parental report. It could be argued that some of the differences measured are due to the mothers of the treatment group observing their children more closely than the mothers of the control group. However, there was also a statistically significant difference on the performance scale, which is objectively assessed, making it likely that the other improvements were real.

The facilitated language development in the treatment group is an important finding because of its significance in aiding development of communication and the acquisition of other skills. It is of great help to the mother if she can understand what her child requires and dispels her fear about the child's acquisition of speech.

One of the important effects of the treatment was the change in the mothers' pattern of daily care of their children who became more independent and exploratory within the home. This contrasted with the mother's initial statements that their Down's syndrome child was nonprogressive, noncreative, and engaged in routine activities when playing alone. Before treatment an unduly active child was often inhibited because the play was annoying but the group meetings worked out ways of replacing naughty behaviour with constructive alternatives.

Carr (1971) reported that mothers with a Down's syndrome child apply different discipline to such a child, i.e. less punishment or fewer rewards as they felt the child was not capable of understanding. This was borne out by the comments of the mothers in the first sessions in this study and, during the treatment which aimed at purposeful communication, the mothers' expectations towards the child seemed to be modified.

It is possible that the beneficial effects of training Down's syndrome children are paralleled in children with other handicaps. We are currently exploring this possibility with the hope of helping brain damaged or defective children. We believe that this study has important practicai implications for the training of Down's syndrome children. It 
should be possible to help many children by these methods, and where there is a shortage of skilled therapists it may be possible to teach aides to be competent in these techniques and to use them in the children's homes under skilled supervision.

We express our appreciation to the Clinical Research Fund of the Welsh Hospital Board for financial assistance; to the staff of the Glamorgan County Council Health Department and Cardiff City Health Department for their help in this study; to Mrs. Anne Chilcott for the preparation of this manuscript. We thank Dr. Graham Melville Thomas, Consultant Child Pyschiatrist, and Mr. Rex Brinkworth, Education Adviser, for encouragement and help, and also the mothers for their participation in this study.

\section{REFERENCES}

Bensberg, G. J., Colwell, C. N., and Cassel, R. H. (1965). Teaching the profoundly retarded self-help activities of behaviourshaping techniques. American fournal of Mental Deficiency, $69,674$.

Berkowitz, B. P., and Graziano, A. M. (1972). Training parents as behaviour therapists: a review. Behaviour Research and Therapy, 10, 297.

Bricker, W. A., and Larsen, L. A. (1968). A manual for parents and teachers of severely and moderately retarded children. Imrid Papers and Reports, 22.

Brinkworth, R. (1967a). Care and Training for the Baby with Down's Syndrome, 4th ed., parts I and II. Down's Babies Association, Birmingham 1971.

Brinkworth, R. (1967b). Effects of Early Treatment and Training on the Mongoloid Infant. (Unpublished dissertation. University of Birmingham School of Education).

Brinkworth, R. (1967-71). Pamphlets on Care and Training for the Baby with Down's Syndrome, various eds. Londonderry Education Committee 1967. N.S.M.H.C. Birmingham 1969-70. Down's Babies Association, Birmingham 1971.

Brinkworth, R. (1972). The unfinished child. Effects of early home training on the mongol infants. Mental Retardation and Behavioural Research. Study Group No. 4. Ed. by A. D. B. Clarke and A. M. Clarke. Churchill Livingstone, Edinburgh and London.

Carr, J. (1971). A comparative study of the development of mongol and normal children from $0-4$ years. Ph.D. Thesis. University of London.

Centerwall, S. A., and Centerwall, W. R. (1960). A study of children with mongolism reared in the home compared to those reared away from the home. Pediatrics, 25, 678 .

Cunningham, C., and Jeffree, D. M. (1971). Working with Parents. National Society for Mentally Handicapped Children and Hester Adrian Research Center, Manchester.
Goldstein, H. (1964). Mentally retarded children in special programs. Fournal of Education, 147, 95.

Griffiths, R. (1954). The Abilities of Babies. A Study in Menta Measurement. University of London Press, London.

Griffiths, R. (1970). The Abilities of Young Children. A Comprehensive System of Mental Measurement for the First Eight Years of Life. Child Development Research Centre, London.

Howlin, P., Marchant, R., Rutter, M., Berger, M., Hersov, L., and Yule, W. (1973). A home-based approach to the treatment of autistic children. Fournal of Autism and Childhood Schizophrenia, 3, 308.

Jones, O. H. M. (1974). Mother-care communication with very young mongol children and its influence on the child's development of communication skills. Paper presented at Child Development Research Unit, University of Nottingham.

Levinson, A., Friedman, A., and Stamps, F. (1955). Variability of mongolism. Pediatrics, 16, 43.

MacAulay, B. D. (1968). A program for teaching speech and beginning reading to nonverbal retardates. Operant Procedure in Remedial Speech and Language Training. Ed. by H. N. Sloane and B. D. MacAulay. Houghton Mifflin, Boston.

Maxwell, A. E. (1970). Basic Statistics in Behavioural Research. Penguin Books, Harmondsworth, Middlesex.

Melyn, M. A., and White, D. T. (1973). Mental and developmental milestones of non-institutionalized Down's syndrome children. Pediatrics, 52, 542.

Mittler, P. (1974). A rationale for parental partnership. Paper presented at Hester Adrian Research Centre, Manchester. (Abst.) Bulletin of the British Psychological Society, 27, 174.

Patterson, G. R. and Gullion, M. E. (1968). Living with Children. New Methods for Parents and Teachers. Research Press, Illinois.

Rentfrow, R. K., and Rentfrow, D. K. (1969). Studies related to toilet training of the mentally retarded. American fournal of Occupational Therapy, 23, 425.

Santostefano, S., and Stayton, S. (1967). Training the pre-school retarded child in focusing attention; a program for parents. American fournal of Orthopsychiatry, 37, 732.

Sloane, H. N., Johnston, M. K. and Harris, F. R. (1968). Remedial procedures for teaching verbal behaviour to speech deficient or defective young children. Operant Procedure in Remedial Speech and Language Training. Ed.by H. N. Sloane and B. D. MacAuley. Houghton Mifflin, Boston.

Stedman, D. J., and Eichorn, D. H. (1964). A comparison of the growth and development of institutionalized and home-reared mongoloids during infancy and early childhood. American Fournal of Mental Deficiency, 69, 391.

Watson, L. S. (1972). How to use behaviour modification with mentally retarded and autistic children: programmes for administrators, teachers, parents and nurses. Behaviour Modification Technology. Watson, Columbus, Ohio.

Watson, L. S. (1973). Child Behaviour Modification. A Manual for Teachers, Nurses and Parents. Pergamon, Oxford.

Correspondence to Professor O. P. Gray, Department of Child Health, The Welsh National School of Medicine, Heath Park, Cardiff CF4 4XN. 